\title{
INTERCALARY STAPHYLOMA IN A CASE OF HERPES ZOSTER OPHTHALMICUS* ${ }^{\dagger}$
}

\author{
BY \\ W. DUGMORE \\ Victoria Hospital, Burnley, Lancashire
}

OCULAR complications occur in about half the cases of herpes zoster ophthalmicus (Duke-Elder, 1938), the commoner ones being keratitis and iridocyclitis. Among the rarer complications is scleritis, which usually occurs late, in association with iridocyclitis and frequently with paralytic mydriasis (Duke-Elder, 1938). There is no report in the literature of an intercalary staphyloma occurring as a sequel to herpes zoster ophthalmicus, so that the following case report may be of interest.

\section{Case Report}

A man aged 80 was referred to the Out-patients Department on March 24, 1965, with a history of herpes zoster ophthalmicus in the right eye of one month's duration. He complained of pain in the distribution of the ophthalmic nerve, and of dimness of vision in the right eye.

Examination.-The visual acuity was $6 / 24$ in the right eye and 6/6 in the left. Hutchinson's sign was positive. There was marked conjunctival hyperaemia and corneal sensation was depressed. The right pupil was dilated and did not react to light (paralytic mydriasis). No mydriatics had been instilled. The slit lamp showed punctate epithelial staining, a flare, and numerous "muttonfat" keratic precipitates.

Treatment.-The patient was admitted to hospital and treated with guttae atropine and chloramphenicol.

Progress.-On March 31 slit-lamp examination showed slight corneal staining. There was no flare and the keratic precipitates were now pigmented. The ocular tension was normal in each eye. On April 3 there was slight ptosis of the right upper lid.

On April 10 there was no corneal staining, flare, or keratic precipitates, but iridoplegia was still present. The patient was discharged from hospital on no treatment.

On May 11 there was no corneal staining, and no activity in the anterior chamber. The intraocular pressure in the right eye was $34 \mathrm{~mm}$. $\mathrm{Hg}$ using a $5.5 \mathrm{~g}$. weighted tonometer. He was treated with Diamox, $250 \mathrm{mg}$. twice daily, and 2 days later the pressure had fallen to $20 \mathrm{~mm}$. $\mathrm{Hg}$. The Diamox was gradually reduced and was stopped on July 14,1965 , when the remaining symptoms were iridoplegia and reduced corneal sensation.

Relapse.-On November 2, 1965, the patient, who had defaulted from the Out-patients clinic returned complaining of pain and redness in the right eye for 4 days, with further deterioration in visual acuity. He was most definite about the duration of his symptoms. The visual acuity in the right eye was 6/60. Diffuse brawny scleritis was present and the eye was tender. Slitlamp examination showed gross corneal staining and diffuse stromal keratitis. It was difficult to see into the anterior chamber because of the keratitis, but there was no doubt about the presence of numerous "mutton-fat" keratic precipitates. The tension was raised to digital pressure, but tonometric readings were not attempted because of the corneal ulceration. At 2 o'clock in the intercalary region was an elevated pigmented nodule of about $7 \times 5 \mathrm{~mm}$. The sclera was smooth and thinned over the swelling and no lobules were present. The nodule transilluminated brilliantly and showed no dark striae.

* Received for publication January 7, 1966.

$\dagger$ Address for reprints: as above. 
Treatment.-The patient was admitted to hospital and given a course of prednisone tablets $10 \mathrm{mg}$. 8-hrly; this dosage was gradually reduced.

On November 22, 1965, the right eye was white and slit-lamp examination showed no corneal staining, flare, or keratic precipitates. The tension was normal.

Result.-At the time of writing the staphyloma has not altered in shape or size, but satellite areas of healed scleritis with a superior curtain of corneal oedema continuous with the limbus and projecting into the cornea for $2 \mathrm{~mm}$. are present (Figure).

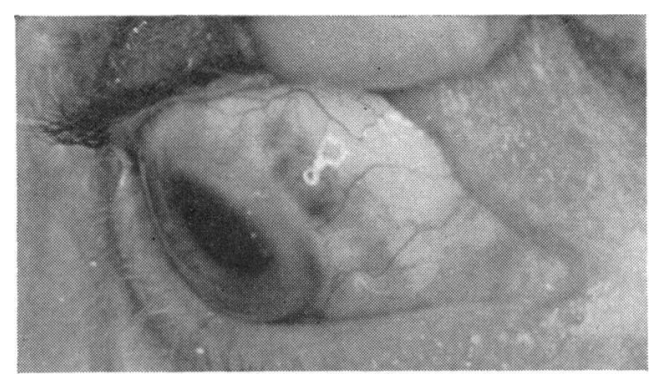

FIGURE.-Appearance after treatment.

\section{Comment}

Anterior staphylomata were differentiated by Arlt (1851-56) into ciliary and intercalary, the latter being distinguished by the absence of the dark striae of the ciliary processes on transillumination and by the anterior border. In the present case the following points are of interest:

(1) The staphyloma appeared 8 months after the onset of herpes zoster ophthalmicus.

(2) From the history it would appear that the two factors associated with the occurrences of scleral staphylomata, namely decreased scleral resistance and/or a rise in intraocular pressure, were present for only 4 days before the appearance of the staphyloma.

(3) The early appearances of iridocyclitis and iridoplegia in the affected eye indicate that scleritis may occur later.

(4) There was no nodular scleritis, but a diffuse scleritis preceded the staphyloma by only a few days. Though the scleral inflammation was diffuse there was only a localized decrease of scleral resistance.

(5) The initial rapid improvement in the keratitis and iridocyclitis without the use of topical or systemic corticosteroids.

I wish to thank Dr. G. Behr for taking the photograph and Miss E. Holmes for her help in the preparation of the paper.

\section{REFERENCES}

ARLT, F. (1851-56). "Die Krankheiten des Auges". Credner and Kleinbub, Prague.

DUKE-ElDER, S. (1938). “Text-Book of Ophthalmology", vol. 2, p. $1904 . \quad$ Kimpton, London. 